\title{
Behavioral Economics through the Lens of Persuasion Context Analysis: A Review of Contributions in Leading Information Systems Journals
}

\author{
Michael Oduor ${ }^{10000-0003-2066-4587]}$ and Harri Oinas-Kukkonen \\ Oulu Advanced Research on Services and Information Systems \\ Faculty of Information Technology and Electrical Engineering, University of Oulu, \\ P.O. Box 8000, 90014 Oulu, Finland \\ \{michael.oduor, harri.oinas-kukkonen\} @oulu.fi
}

\begin{abstract}
As technology becomes an integral part of our everyday lives, the more crucial it is to investigate how it can be further harnessed to improve individuals' wellbeing. This involves studying users' interactions with technology, how different design techniques influence their use, and the factors that might lead to sub-optimal use of technology. Such factors include decision biases which are mostly investigated in behavioral economics research. Behavioral economics counters the arguments of standard economic theories and combines psychological theories and economics to study how people actually behave as opposed to how they should behave as rational beings. Thus, this review provides an overview of behavioral economics research in the major IS journals. The aim is to determine the extent of such research within the IS field. An electronic search of the major IS journals was conducted over an 8-year period and the findings were categorized according to the use, user and technology contexts of the persuasive systems design model. The findings reveal the need for awareness of how various behavioral economic principles (or decision biases) influence decision making in technology-mediated settings and the development of strategies to mitigate their influence.
\end{abstract}

Keywords: Behavioral Economics, Persuasive Systems Design, Information Systems.

\section{$1 \quad$ Introduction}

Increase in the complexity of the environment and its speed of change requires more knowledge about the mechanisms and processes that the economic man uses to relate himself to that environment and to achieve his goals. Normal economic thought is not concerned with individual behavior because it is based on the assumption that the economic actor is rational. Hence, it is thought to be possible to make strong predictions about human behavior without actual observation, and that competition implies only the rational survive [1].

In psychological theories, the motive to act stems from drives and action terminates when the drive has been fulfilled. Furthermore, the conditions for satisfying a drive are 
not fixed, but may be defined by an aspiration level that itself adjusts upward or downward on the basis of experience and the prevailing situation. What is natural and intuitive in a given situation is not the same for everyone; different cultural experiences favor different intuitions about the meaning of situations, and new behaviors become intuitive as skills are acquired [1,2]. Behavioral economics examines the factors that influence the consumption of goods and services. It combines psychology and economics to investigate individuals' actual behavior as opposed to how they are expected to behave when considered as perfectly rational beings seeking to maximize their utility $[3,4]$. Behavioral economics, organized around experimental findings, counters the arguments of the standard economic theories. It focuses on examining individuals' choices, the motives underlying these choices and increased understanding of a subject's situation at the time of making a choice [5].

The present study, an extension of Oduor \& Oinas-Kukkonen [6], analyzes behavioral economics in information systems (IS) research by using persuasion context analysis as described in [7]. Applying behavioral economics methods to study the use and adoption of digital interventions can be a potential avenue for better understanding users' requirements, how users interact with technology and the factors that hinder their adoption and/or use. Many technologies fail, not because of technical problems, but rather due to a lack of careful consideration of human and other nontechnology issues in the design and implementation process of these systems [8]. Therefore, behavioral economics with its focus on how people actually behave [9], has enormous potential to inform and complement IS research. Especially, as there has not been extensive research in the IS field utilizing behavioral economics methods [10].

The objective of the present review is, thus, to examine by applying context analysis [7], behavioral economics research in IS that address how cognitive limitations influence decision-making. The rest of the paper is structured as follows: the following section introduces the theoretical background on behavioral economics and persuasive systems design. Section 3 describes the review process. Section 4 presents the results. The paper then concludes with a discussion summarizing the results, addressing the limitations, directions for future work and the conclusions.

\section{Theoretical Background}

\subsection{Persuasive Systems Design}

A large body of research shows that computer-based interventions can be efficacious $[11,12]$. Computers can operate as tools, mediums and social actors that increase capability, provide interactive experiences and create relationships [13]. With their increased interactive and persuasive capabilities, computers can, therefore, be used to motivate positive behavior change in users. Especially, as the aim of persuasive communication is to voluntarily change users' attitude and/or behavior without deception or coercion [7], [13].

Behavior modification is important for any type of intervention because behavior is central to the development, prevention and management of preventable diseases and 
health conditions. Its role in maintaining a healthy lifestyle is substantial and encompasses prevention of diseases, enhancement of health and overall quality of life [14], [15]. Therefore, designing systems to change people's behavior requires a thorough understanding of the problem domain and the underpinning theories and strategies of persuasive systems design [8]. Research by Kelders, Kok, Ossebaard, \& Van GemertPijnen [16] showed the importance of persuasive systems design in influencing users adherence to web-based interventions.

Oinas-Kukkonen \& Harjumaa [7], developed the persuasive systems design (PSD) model; a conceptual framework used to analyze, design, and evaluate the persuasion context and the related techniques for implementing persuasive systems [7], [8]. The model helps to organize thoughts about a persuasive system by mapping persuasive design techniques to the system's requirements [17]. The model outlines the development process of persuasive systems and consists of postulates, persuasion context analysis and the design or evaluation of persuasive systems ([7].

The postulates consider the psychological principles behind the design of persuasive systems and they address the neutrality of technology, ease of use of digital interventions, the making and enforcing of commitments, the effective routes to persuasion, the sequential nature of persuasion, the ideal moments for initiating persuasive features and openness of persuasive systems [7].

These postulates are based on social psychological theories on attitude change, influence, learning among others that help explain the factors that influence human behavior in different situations. Such theories include the theory of planned behavior (TPB) [18]. The elaboration likelihood model (ELM) [19] that describes direct and indirect routes to information processing and persuasion. Bandura's [20] social learning and social cognitive theories which describe how people learn new behaviors by studying, observing and then replicating the actions of others. Lastly, Cialdini's [21] studies on influence which show how formulating requests in certain ways can trigger automatic compliance response from individuals.

Persuasion context is where system designers select the behavioral changes that they would like to encourage and the strategies for doing so [17]. A common definition of context was provided by Dey [22], who stated: "Context is any information that can be used to characterize the situation of an entity. An entity is a person, place, or object that is considered relevant to the interaction between a user and an application, including the user and applications themselves". The persuasion context analysis comprises of recognizing the intent, the event, and the strategy [7]. The intent consists of the reasons for developing a system and how the system will be used. Plus, determining who the actual persuader is. The event consists of the context of use, the user, and the technology. The use context refers to characteristics of the problem domain in question, the user context refers to characteristics of the individual user, and the technology context refers to the technical specifications of a system. Finally, the strategy addresses the analysis of persuasive message being conveyed and the route, whether direct or indirect or both [19], that is used to influence the user [7]. 


\subsection{Behavioral Economics}

Only in economics is the individual modelled as a logical and consistent set of preferences and certain cognitive facilities [23]. A standard argument in economics and management has been that consumers want to maximize utility and if presented with clear and simple choices that they understand, they will do so. Whereas to behavioral scientists, the real world is so complicated that the theory of utility maximization has little relevance to real choices and even in relatively simple situations, people do not behave in the way predicted by direct application of the utility theory [1]. This stream of research formed the beginnings of behavioral decision research. The 1970s heralded the emergence of behavioral economics with studies investigating judgment under uncertainty, individual's inherent biases and how this influenced their decision making under conditions of risk $[24,25]$. Behavioral economics research has shown how, through requests, judgments can be developed and are, consequently, often influenced by factors in the environment in which the judgements are developed [24, 25]. Additionally, research has also demonstrated how differences in formulating a choice of problems cause significant changes in people's preferences. Angner \& Loewenstein [26], for example, provide more details on the emergence of behavioral economics.

Behavioral economics acknowledges that human beings: 1) have limited information processing capabilities which lead to their adoption of rules of thumb to aid in problemsolving. 2) do not always make choices that are in their best long-term interest, due to a lack of self-control, and 3) are not always motivated by pure self-interest and their actions can also include altruistic and spiteful behaviors [4]. These traits are explained by psychological principles that consider people's actions in different situations. For example, one's estimates and judgments being biased towards some initial anchor value, preference of the status quo as opposed to changing routines, interventions that help participants pre-commit to future healthy behavior and so forth [4], [27].

Most behavioral economics research mainly focuses on interventions for healthier living [3], [28], strategies for reducing unwanted behaviors [29], environmental sustainability and improving governmental and institutional policies that benefit society [30], [31]. Prince et al. [3], for example, in their review aiming to improve assessment instruments for reducing alcohol involvement among college students, propose improvements to better understand the role of protective behavioral strategies in reducing the use of alcohol and explain why there have been inconsistencies in previous studies and what can be done to enhance future studies. Michie and Williams [28] examine the factors that lead to work-related psychological ill health in different professions and propose solutions that mainly involving training and increased involvement in decision making.

Siva [30] applies lessons in behavioral economics to study how people respond to incentives and the reasons why pay-for-performance programs are flawed and how they can be improved. Lunze and Paasche-Orlow [29] discuss the pros and cons and ethical concerns on the use of incentives in behavioral economics research to promote healthy behavior and reduce health costs. The need for safeguards in the programs to monitor their associated risks and promote fairness in offering the incentives for them to be beneficial is acknowledged [29]. Avineri [31], links travel behavior to psychological 
theories and shows how individuals' choices in different contexts deviate from the predictions of rational behavior.

In more technical interventions, [32], for example, apply behavioral economics in developing sensor-based interactive systems to initiate change in residential energy consumption. They argue that even though the success of most of the sensor-based power meters and other related residential monitoring devices depends on users responding to the data they generate with appropriate changes in their consumption behavior, most of these devices have not been developed with the end-user in mind. Therefore, a more human-centered process that integrates behavioral insights to determine the effectiveness of sensor-based interactive systems and of interfaces based on cognitive, social and affective frames is proposed [32]. King, Greaves, Exeter, \& Darzi [33], in their short study on influencing health behavior with games, state that games are designed to influence people's behavior. Whether knowingly or not, insights from behavioral economics which has recognized numerous ways to counter sub-optimal decision making are related to many of the gamification features used to enhance engagement. For example, conditional rewards (points, prizes etc.) are dependent on frequently playing the games and there is a risk of loss if play is not resumed after an interruption or a break from playing (explained by loss aversion) [33].

\section{Review Process}

A structured literature review is a focused approach to identify relevant articles. Structured reviews provide means to identify and categorize most of the existing literature concerned with the research question(s). The reasons for conducting a review include, but are not limited to summarizing the existing facts about use of technology, creating a firm foundation for advancing knowledge, identifying gaps in current works in order to suggest areas for further analysis, and providing a framework for suitably positioning research interests [34, 35]. Our objective, is to use the PSD model [7] to examine behavioral economics research in IS. This is to enable the identification of any recurring and emerging themes and discern relevant techniques for apply the principles to improve the development of IS.

Kitchenham [35] describes a set of review guidelines a modification of which was used to define the problem, analyze the data and come up with concise conclusions. The steps include: 1) identification of the need for a literature review, 2) formulation of research questions, 3) searching for relevant articles, 4) selecting the primary studies, 5) assessing and recording the quality of included studies, 6) extracting data from the included studies, and 7) synthesizing data and summarizing the results [35].

\subsection{Need for a Review of Behavioral Economics in Information Systems}

Webster and Watson [34] state that a literature review process stems from 1) scholars need to report progress in a particular stream of research and, 2) from those who have completed a review prior to starting a project and have developed theoretical models 
from the review. Additionally, there are reviews on mature topics and those on emerging issues that would benefit from exposure to new theoretical foundations ([34]. Behavioral economics has lately been gaining attention in the IS field, and although still relatively new, it has been widely studied in finance and economics, health and wellness and sustainability-related topics.

Vassileva's [36], analysis of the growth of web-based social applications and the approaches they use to motivate user participation, states that most of the applications employ simple techniques that have succeeded in engaging users. Such techniques, though, only ensure that users follow instructions, but are unable to guide the social system(s) towards a desirable overall behavior. For this reason, several future trends related to the application of social psychology, behavioral economics and their convergence with other disciplines are suggested in the design of reward and incentive mechanisms for particular types of communities, persuasive and other user-adaptive systems [36]. Goes [10], further explains how behavioral economic principles can be combined with IS research in areas such as recommendation systems, collective intelligence and gamification. Goes [10], also suggests online social environments as unexplored directions in which the two can travel together.

As the role of information technology (IT) increases in people's daily decision making and experiences, new opportunities to assist people in making self-beneficial choices have arisen [37]. This is important as most studies on persuasive systems and success factors for IS, rarely address the context and the effect it can have on a user's decision-making. Success is also usually measured in terms of changing users' behaviors in ways predetermined by developers or providers of the system [38]. In persuasive systems, information is usually provided for people to better understand certain problems. However, Lee et al.'s [37] research has noted potential disadvantages of using information-centric approaches to motivate behavior change. The emphasis on information-centric approaches rests on the assumption that people are rational actors striving to enhance their utility based on what they know and the available information [38, $39,40]$. But people have been shown to be predictably irrational with such behavior being "neither random nor senseless. They are systematic, and since they are repeated again and again, predictable" [9].

Therefore, the is a great need for more understanding about the influence factors on individuals' choices in the context of persuasive and information systems in general [41]. Furthermore, there is an opportunity to combine behavioral economics and IS as these two disciplines both seek to enhance the understanding of the user. Both disciplines emphasize how context and cognitive effects influence decision making-the IS field is mostly about information processing for decision-making [10]. Subsequently, we have examined articles from the top IS journals and have not found a comprehensive review that addresses the research question below regarding the integration of behavioral economic in IS to study the use of technology.

The main research question that guided our review is:

RQ: How can behavioral economics enhance understanding of users and their interactions with information systems? 


\subsection{Electronic Search}

For the present review, a literature search was conducted for the years between 2006 and 2014. The keywords used were behavior(u)ral economics, prospect theory, mental accounting, cognitive bias, choice architecture, nudge, persuasive systems design, persuasive technology, behavior(u)r change, attitudes, and persuasion. This was to ensure that we got a wide variety of articles applying both behavioral economics principles and persuasive techniques.

The above keywords were used to search the metadata related to the top eight IS journals (MIS Quarterly, European Journal of Information Systems (EJIS), Information Systems Journal (ISJ), Information Systems Research (ISRe), Journal of Information Technology (JIT), Journal of Management Information Systems (JMIS), Journal of Strategic Information Systems (JSIS), Journal of the Association for Information Systems (JAIS)) in Wiley, INFORMS PubsOnline, EBSCOhost, ScienceDirect, Taylor Francis Online, and ProQuest ABI/INFORM.

The search string resulted in 919 articles and after excluding editorials, book reviews and commentaries, and reviewing the abstracts, 63 articles remained, these were further reduced to 15 (Figure 1) based on the eligibility criteria below.

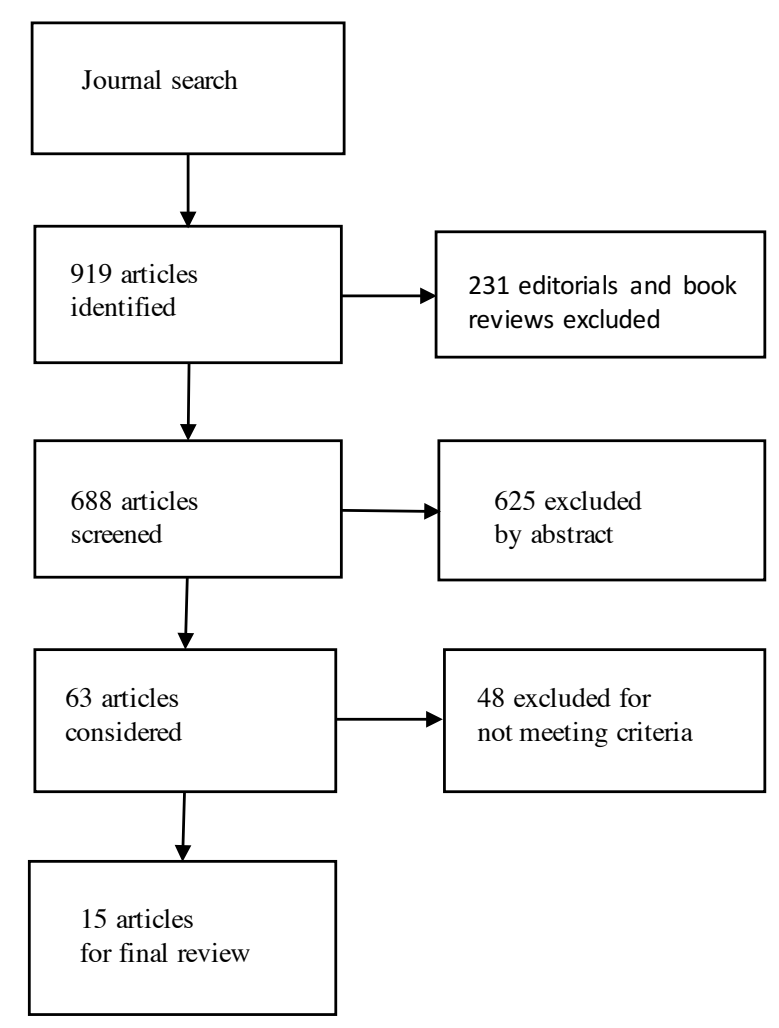

Fig. 1. Literature search and selection process [6]. 


\subsection{Eligibility Criteria}

The following inclusion and exclusion criteria were used to select articles for answering our research question. Studies were selected if they, a) had behavioral economics in the abstract, b) were full research papers (and not editorials, commentaries), c) described the persuasive/cognitive stimuli applied, d) examined the relation between the stimuli and (behavioral) outcome. Articles were excluded, if they: a) only discussed system implementation; b) were about either general systems development or systems development to meet organizational/individual needs without a behavioral outcome; c) only discussed systems benefit(s) to an organization; or d) were purely on research methodology or systematic reviews not related to the topic.

\subsection{Data Extraction and Synthesis}

The first author coded all the articles using predefined criteria (devised by both authors) and any uncertainty about a particular article was discussed prior to its inclusion or exclusion based on the eligibility criteria.

Each selected publication was examined for the following elements: Objective of the study and corresponding research question(s); study environment and participants; themes emerging from the study; and, the relevance of the studies' results. This was then followed by a synthesis of the emergent themes and categorization of the articles according to the judgement and decision-making principle studied. To integrate the search results and our conceptualization of behavioral economic studies in IS we applied context analysis as defined by Oinas-Kukkonen and Harjumaa [7] to categorize the articles (Tables 1-3) according to the objectives, the cognitive principle(s) studied, the user and technology contexts, and contribution of the study. This categorization is suitable because of the level of abstraction it enables in identifying the effects of the measures used in the reviewed studies.

\section{$4 \quad$ Results}

Analysis of these papers was based on the aforementioned objectives and the results reveal a difference in coverage of behavioral economics in the major IS journals. A majority of the articles were from EJIS and ISRe. All but one of the journals produced original results with data, and only two of the articles [42, 43] from ISRe contained behavioral economics as a keyword in their abstracts. While the following analysis is based on the 15 articles that we have labeled as investigating a behavioral economic principle, it is important to note that certain articles [42]-[51] more strongly considered decision-making and the valuation of presented choices than others (e.g., [52, 53]. Lankron \& Luft [54] and Legoux et al. [48] did not include a technical artifact, but analyzed the effects of the behavioral economics principles on investment decisions.

Some articles, while explicitly focused on investigating users' valuation of choices, additionally considered goals and other design issues that may not fall under the realm of behavioral economics. Accordingly, our classification of each of these articles as investigating a behavioral economics principle should be considered with this caution 
in mind. As further noted in [31], it is important to acknowledge that behavioral economics is not a homogenous field that can straightforwardly be distinguished and there are opposing views as to what counts as behavioral economics. A related discussion can be found in a Q \& A with R. Thaler on what it really means to be a "Nudge" [55]. The characteristics of the studies based on the principle examined are presented in Tables 1-3.

Analysis of the persuasion context requires an understanding of the occurrences in information processing as the context assists in learning and better understanding user behavior.

\subsection{The Intent}

Intentions arise from the creators of interactive systems, those who give access to the system, and the individuals using the systems [7], [13]. In the case of the current study, the intent is derived from both the objectives of the reviewed studies. Most of the studies were either Web or mobile-based and involved either experimentation [42], [45] or surveys [44], [46] Six of the studies investigated various aspects of user behavior in online stores. Chiu, Wang et al. [47] apply prospect theory [25] to investigate decisionmaking under risk and the reasons people continue to buy from an online store. Prospect theory is used to explain decision-making from a value maximizing perspective and how, when one makes a decision, $\mathrm{s} / \mathrm{he}$ does not take into account the decision's effect on their consumption [47].

Blanco et al. [52] develop mock-ups based on e-commerce practices to investigate the ideal combination of presenting visual and textual information and how various combinations of these affect consumers' cognitive states. Wu and Gaytán [45] discuss a risk-based conceptual framework to help understand the role of seller reviews and product prices on buyers' willingness to pay. Wu and Gaytan [45] apply the buyers' risk perspective to explain conflicting results in previous studies. Adomavicius et al. [43] investigate the influence of recommender systems' ratings on consumers' preferences at the time of consumption by exploring anchoring, timing, system reliability and granularity issues that are related to their impact. Goh and Bockstedt [42] apply behavioral economic principles to examine seller's design choices and how these choices influence consumer behavior. Goh and Bockstedt [42] investigate how framing a multipart pricing scheme can influence consumers perceived value of customizable bundle offers.

Lankton and Luft [54] apply behavioral economic theories to study IT investment valuation and predict the differences between intuitive judgment and real options prescriptions. Ma et al.'s [56] study integrate gambling theory, the availability heuristic, and repeated behavior into a framework that explains online gambling over time. The rest of the studies examine various aspects of human behavior in different environments. These include, the role price and context play in mobile service adoption and the use of location based services in relation to cognitive processes $[49,50]$ and the role consumer trust in online merchants plays in purchase decisions [57]. 


\subsection{The Event}

The event consists of the use, user and technology contexts. These are the issues arising from the problem domain, individual user differences that influence their information processing, and the technologies or strategies employed in computer-human and computer-mediated interaction [7]. The use context was not discussed in detail in any of the studies. This is because they primarily investigated some aspect of user behavior related to valuation of choices and/or how presented information influences users' decisions without going into details on the actual use of the systems or features investigated. As noted in [8] a high abstraction level in systems descriptions makes it difficult to understand the actual interactions taking place through the system and the extent to which any potential outcome(s) are due to the system's intent.

The hypotheses and research design of the reviewed studies provided a clearer picture of the impact and the relevance of the research results. For example, Chiu et al.'s [47] study extended prospect theory and provided additional theoretical reasons why consumers become more risk-seeking or less risk averse in different circumstances. One of the practical implications of their study was a suggestion of how online sellers could attract potential buyers and turn infrequent buyers into frequent ones. This was through delivering guarantees on issues such as security, inspiring customers and keepings customers informed [47].

The studies analyzed were about, 1) Web-based environments which analyzed how users value presented options and make decisions (e.g. [43], [47], [52], [56]), 2) ways of improving user interactions [48], 3) mobile-based services [50], and 4) the decision to use certain systems [49]. Although these studies reported the technology context, as their focus was mostly on studying users' actions, they did not provide a detailed description of the technologies investigated.

\subsection{The Strategy}

Analysis of the strategy involves identifying the underlying theories applied in the research to examine user behavior, the medium used, and the persuasive techniques that are applied. It is only in the Angst and Agarwal [51] study that there is a mention of the route. The study, investigating privacy concerns, is explicitly about direct and indirect routes to persuasion. The study highlights under which circumstances either or both routes could be used. Unlike previous studies on the ELM where the main focus was on attitude/opinion change, Angst and Agarwal [51] investigated a choice process that could be cognitively taxing.

The message refers to the techniques used to influence or alter users' actions and, in our study, these are the principles (see Tables 1-3) applied in or emerging from the reviewed articles. These included: 1) How people make different decisions based on the same set of options depending on how the options are presented (framing) (e.g., [42]). 2) Relying only on information that confirms an initial assumption while discounting opposing information (confirmation bias) (e.g., [46]). 3) how people tend to experience (possible) losses more than (possible) gains, making them risk averse when options are described in terms of gain and risk seeking when they are describe in terms 
of losses (e.g., [47]). 4) When decision makers begin with an initial value and adjust it as needed in order to arrive at decisions. This leads to bias as any decisions made are skewed toward the initial anchor (anchoring) (e.g., [43]). and 5) Applying persuasive principles (explained by information processing-related theories such as the ELM in investigating choice decisions) in Websites to influence users [51].

Table 1. Characteristics of studies related to framing [6].

\begin{tabular}{|c|c|c|c|c|}
\hline Study & Objective & $\begin{array}{l}\text { User } \\
\text { Context }\end{array}$ & $\begin{array}{l}\text { Technology } \\
\text { context }\end{array}$ & Contribution \\
\hline [52] & $\begin{array}{l}\text { Examine how } \\
\text { product presenta- } \\
\text { tion affects recall } \\
\text { and perceptions on } \\
\text { quality (framing) }\end{array}$ & $\begin{array}{l}\text { Graduate } \\
\text { and Post- } \\
\text { graduate } \\
\text { students } \\
(\mathrm{N}=108)\end{array}$ & $\begin{array}{l}\text { Mock web- } \\
\text { sites based } \\
\text { on e-com- } \\
\text { merce prac- } \\
\text { tices }\end{array}$ & $\begin{array}{l}\text { Confirmation of the im- } \\
\text { portance of product } \\
\text { presentation online, } \\
\text { consumer characteris- } \\
\text { tics, and how people } \\
\text { perceive and process } \\
\text { product information }\end{array}$ \\
\hline [42] & $\begin{array}{l}\text { Measure whether } \\
\text { framing influences } \\
\text { consumers' value } \\
\text { of customizable } \\
\text { bundle offers from } \\
\text { online stores } \\
\text { (framing) }\end{array}$ & $\begin{array}{l}\text { Behavioral } \\
\text { experi- } \\
\text { ments } \\
(\mathrm{N}=454)\end{array}$ & $\begin{array}{l}\text { Online } \\
\text { streaming } \\
\text { and movie } \\
\text { rentals }\end{array}$ & $\begin{array}{l}\text { The technology-driven } \\
\text { context of a purchase } \\
\text { decision can have sig- } \\
\text { nificant effects on con- } \\
\text { sumer choices and eco- } \\
\text { nomic outcomes. }\end{array}$ \\
\hline [44] & $\begin{array}{l}\text { Investigate } \\
\text { whether promi- } \\
\text { nence of privacy } \\
\text { information influ- } \\
\text { ences incorpora- } \\
\text { tion of privacy } \\
\text { considerations in } \\
\text { online purchasing } \\
\text { decisions. (Sali- } \\
\text { ence, framing, and } \\
\text { priming) }\end{array}$ & $\begin{array}{l}\text { Online re- } \\
\text { sponses to } \\
\text { a concerns } \\
\text { survey and } \\
\text { a shopping } \\
\text { experi- } \\
\text { ment } \\
(\mathrm{N}=238)\end{array}$ & $\begin{array}{l}\text { Shopping } \\
\text { search en- } \\
\text { gine inter- } \\
\text { face, Pri- } \\
\text { vacy Finder }\end{array}$ & $\begin{array}{l}\text { New insight into con- } \\
\text { sumers' valuations of } \\
\text { personal data and evi- } \\
\text { dence that privacy infor- } \\
\text { mation affects online } \\
\text { shopping decision-mak- } \\
\text { ing. }\end{array}$ \\
\hline [51] & $\begin{array}{l}\text { Investigate } \\
\text { whether persua- } \\
\text { sion can change at- } \\
\text { titudes and opt-in } \\
\text { intentions toward } \\
\text { electronic health } \\
\text { records even in the } \\
\text { presence of signif- } \\
\text { icant privacy con- } \\
\text { cerns. (Persuasion } \\
\text { and framing) }\end{array}$ & $\begin{array}{l}\text { Partici- } \\
\text { pants (at- } \\
\text { tendees to } \\
\text { a confer- } \\
\text { ence and } \\
\text { online sur- } \\
\text { vey) } \\
(\mathrm{N}=366)\end{array}$ & $\begin{array}{l}\text { Electronic } \\
\text { health rec- } \\
\text { ords }\end{array}$ & $\begin{array}{l}\text { Even when people have } \\
\text { high concerns for pri- } \\
\text { vacy, their attitudes can } \\
\text { be positively altered } \\
\text { with appropriate mes- } \\
\text { sage framing. These re- } \\
\text { sults as well as other } \\
\text { theoretical and practical } \\
\text { implications are dis- } \\
\text { cussed. }\end{array}$ \\
\hline
\end{tabular}


Table 2. Characteristics of studies related to risk aversion and confirmation bias [6].

\begin{tabular}{|c|c|c|c|c|}
\hline Study & Objective & $\begin{array}{l}\text { User } \\
\text { context }\end{array}$ & $\begin{array}{l}\text { Technology } \\
\text { context }\end{array}$ & Contribution \\
\hline [47] & $\begin{array}{l}\text { Understand reasons for } \\
\text { customers' repeat pur- } \\
\text { chase in online retail } \\
\text { stores and the effect } \\
\text { perceived risk would } \\
\text { have. (Risk aversion) }\end{array}$ & $\begin{array}{l}\text { Custom- } \\
\text { ers of Ya- } \\
\text { hoo! } \\
\text { Kimo in } \\
\text { Taiwan } \\
(\mathrm{N}=782)\end{array}$ & $\begin{array}{l}\text { Yahoo! } \\
\text { Kimo -online } \\
\text { shopping } \\
\text { store }\end{array}$ & $\begin{array}{l}\text { The moderating ef- } \\
\text { fect of perceived } \\
\text { risk, extends pro- } \\
\text { spect theory and } \\
\text { provides additional } \\
\text { theoretical reasons } \\
\text { for risk seeking and } \\
\text { risk averseness in } \\
\text { consumers. }\end{array}$ \\
\hline [45] & $\begin{array}{l}\text { Apply the buyers' risk } \\
\text { perspective to recon- } \\
\text { cile and explain seem- } \\
\text { ingly conflicting re- } \\
\text { sults in previous litera- } \\
\text { ture. (Risk aversion } \\
\text { and framing) }\end{array}$ & $\begin{array}{l}\text { Under- } \\
\text { graduates } \\
\text { students } \\
(\mathrm{N}=78)\end{array}$ & $\begin{array}{l}\text { eBay auction } \\
\text { site (empiri- } \\
\text { cal study) }\end{array}$ & $\begin{array}{l}\text { Customers have } \\
\text { different risk pref- } \\
\text { erences and thus } \\
\text { select sellers with } \\
\text { different risk pro- } \\
\text { files to match their } \\
\text { risk appetites. }\end{array}$ \\
\hline [46] & $\begin{array}{l}\text { Explore the extent in- } \\
\text { vestors are subject to } \\
\text { confirmation bias in } \\
\text { the context of exposure } \\
\text { to information on mes- } \\
\text { sage boards. (Confir- } \\
\text { mation bias) }\end{array}$ & $\begin{array}{l}\text { Investors } \\
\text { in South } \\
\text { Korea } \\
(\mathrm{N}=502)\end{array}$ & $\begin{array}{l}\text { Stock mes- } \\
\text { sage boards }\end{array}$ & $\begin{array}{l}\text { Confirmation bias } \\
\text { plays a great role in } \\
\text { investment deci- } \\
\text { sion-making in nu- } \\
\text { merous contexts } \\
\text { e.g., project man- } \\
\text { agement. }\end{array}$ \\
\hline [48] & $\begin{array}{l}\text { Investigate how ex- } \\
\text { perts' investment deci- } \\
\text { sions are affected by } \\
\text { cognitive biases. (Con- } \\
\text { firmation bias) }\end{array}$ & $\begin{array}{l}\text { Partici- } \\
\text { pants } \\
\text { from a fi- } \\
\text { nancial in- } \\
\text { stitution } \\
(\mathrm{N}=100)\end{array}$ & N/A & $\begin{array}{l}\text { Prediction accu- } \\
\text { racy about market } \\
\text { reactions to IT in- } \\
\text { vestments was } \\
\text { hampered by con- } \\
\text { firmation biases. }\end{array}$ \\
\hline
\end{tabular}

Table 3. Characteristics of studies related to other biases [6].

\begin{tabular}{|c|c|c|c|c|}
\hline Study & Objective & $\begin{array}{l}\text { User } \\
\text { context }\end{array}$ & $\begin{array}{l}\text { Technology } \\
\text { context }\end{array}$ & Contribution \\
\hline [43] & $\begin{array}{l}\text { Explore how prefer- } \\
\text { ences at the time of } \\
\text { consumption are in- } \\
\text { fluenced by recom- } \\
\text { mender systems' pre- } \\
\text { dictions. (Anchoring } \\
\text { effects) }\end{array}$ & $\begin{array}{l}\text { Partici- } \\
\text { pants } \\
\mathrm{N}=216\end{array}$ & $\begin{array}{l}\text { Recom- } \\
\text { mender } \\
\text { systems }\end{array}$ & $\begin{array}{l}\text { Viewers' prefer- } \\
\text { ence ratings are } \\
\text { malleable and can } \\
\text { be significantly in- } \\
\text { fluenced by the rec- } \\
\text { ommendation re- } \\
\text { ceived. }\end{array}$ \\
\hline
\end{tabular}




\begin{tabular}{|c|c|c|c|c|}
\hline [57] & $\begin{array}{l}\text { Explain the role of po- } \\
\text { tential users' trust in } \\
\text { creating intention to } \\
\text { revisit a website } \\
\text { (Bounded } \\
\text { Rationality) }\end{array}$ & $\begin{array}{l}\text { Under- } \\
\text { graduate } \\
\text { MIS stu- } \\
\text { dents } \\
(\mathrm{N}=314)\end{array}$ & $\begin{array}{l}\text { Website } \\
\text { which } \\
\text { redirects } \\
\text { to } 12 \text { other } \\
\text { websites }\end{array}$ & $\begin{array}{l}\text { Consumer trust in } \\
\text { e-vendor plays a } \\
\text { major role in pur- } \\
\text { chasing services }\end{array}$ \\
\hline [50] & $\begin{array}{l}\text { Explore the influence } \\
\text { of reference situa- } \\
\text { tions and reference } \\
\text { pricing on mobile } \\
\text { service users' behav- } \\
\text { ior. } \\
\text { (Reference pricing } \\
\text { and Reference situa- } \\
\text { tion) }\end{array}$ & $\begin{array}{l}\text { Students } \\
\text { and em- } \\
\text { ployees } \\
\text { in the } \\
\text { public } \\
\text { sector } \\
(\mathrm{N}=74)\end{array}$ & $\begin{array}{l}\text { Mobile } \\
\text { services }\end{array}$ & $\begin{array}{l}\text { The benefits of ap- } \\
\text { proaching mobile } \\
\text { service adoption } \\
\text { and use research in } \\
\text { a holistic manner } \\
\text { and the importance } \\
\text { of considering the } \\
\text { reference point on } \\
\text { mobile usage be- } \\
\text { haviors. }\end{array}$ \\
\hline [56] & $\begin{array}{l}\text { Develop and test a } \\
\text { model of online gam- } \\
\text { bling that simultane- } \\
\text { ously takes into } \\
\text { account cumulative } \\
\text { and recent outcomes, } \\
\text { and prior use. (Avail- } \\
\text { ability heuristic) }\end{array}$ & $\begin{array}{l}\text { Actual } \\
\text { users of a } \\
\text { gambling } \\
\text { website } \\
(\mathrm{N}=22 \\
304)\end{array}$ & $\begin{array}{l}\text { Bwin } \\
\text { Interactive } \\
\text { Entertain- } \\
\text { ment } \\
\text { (Internet } \\
\text { gambling) }\end{array}$ & $\begin{array}{l}\text { Integration of gam- } \\
\text { bling theory, the } \\
\text { availability heuris- } \\
\text { tic, and repeated be- } \\
\text { havior into a frame- } \\
\text { work that explains } \\
\text { online gambling } \\
\text { over time. }\end{array}$ \\
\hline [49] & $\begin{array}{l}\text { Investigate how cog- } \\
\text { nitive } \\
\text { processes influence } \\
\text { information retrieval } \\
\text { behavior in location- } \\
\text { based services (LBS). } \\
\text { (Cognitive } \\
\text { processes in } \\
\text { decision-making) }\end{array}$ & $\begin{array}{l}\text { Young } \\
\text { smartpho } \\
\text { ne users } \\
(\mathrm{N}=66)\end{array}$ & $\begin{array}{l}\text { Location- } \\
\text { based } \\
\text { services in } \\
\text { the German } \\
\text { telecommu- } \\
\text { nications } \\
\text { market }\end{array}$ & $\begin{array}{l}\text { A new conceptual } \\
\text { framework to in- } \\
\text { vestigate LBS use } \\
\text { and complement } \\
\text { existing models in } \\
\text { user behavior re- } \\
\text { search. }\end{array}$ \\
\hline [53] & $\begin{array}{l}\text { Extend the effort-ac- } \\
\text { curacy } \\
\text { perspective of } \\
\text { understanding users' } \\
\text { recommendation } \\
\text { agents (RA) ac- } \\
\text { ceptance by including } \\
\text { trade-off } \\
\text { difficulty. (Cognitive } \\
\text { aspects of } \\
\text { decision-making) }\end{array}$ & $\begin{array}{l}\text { Students } \\
\text { at a large } \\
\text { North } \\
\text { Ameri- } \\
\text { can uni- } \\
\text { versity } \\
(\mathrm{N}=100)\end{array}$ & $\begin{array}{l}\text { Web-based } \\
\text { recommen- } \\
\text { dation agents }\end{array}$ & $\begin{array}{l}\text { Explains role of } \\
\text { preference elicita- } \\
\text { tion methods } \\
\text { (PEMs) in assisting } \\
\text { users with trade-off } \\
\text { difficulty across } \\
\text { different decision } \\
\text { contexts Perceived } \\
\text { effort compared to } \\
\text { previous research } \\
\text { no longer has a sig- } \\
\text { nificant influence in } \\
\text { the loss condition. }\end{array}$ \\
\hline
\end{tabular}




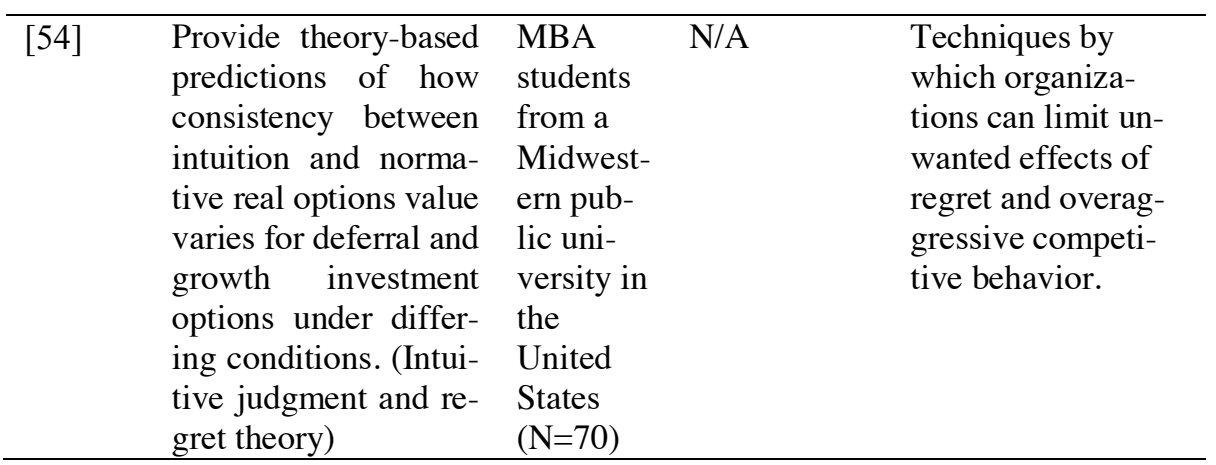

\section{Discussion}

\subsection{Contribution and Implications}

Psychology offers integrative concepts and mid-level generalizations, which gain credibility from their ability to explain apparently different phenomenon in diverse domains. The impressions that become accessible in any particular situation are mainly determined by the actual properties of the objects of judgment. The judgments that people express, their actions, and their mistakes depend on the monitoring and corrective function of their reasoning, as well as on the impressions and tendencies generated by their intuitions [2]. Decision making is also subject to individuals' bounded rationality, which means their inherent limitations can lead to inaccuracies in evaluating information or estimating the value of a product's utility [1].

Therefore, as users' decision making is not always systematic, it is important to understand how this decision making is affected by different contextual issues. Behavioral economic principles can aid in developing techniques for improved presentation, delivery, and organization of information or services. Behavioral economics also helps to highlight how people are influenced by those they are in close contact with, how their actions and reactions are subconsciously shaped by different heuristics and biases, the need to commit to and be consistent with their promises, and the willingness to reciprocate to acts of kindness experienced from others [2], [4], [9], [27], [58].

The influence of behavior and environment are closely integrated. Some environmental influences are possible through their influence on behaviors (e.g., well-maintained walking and cycling paths in neighborhoods). To further complicate issues, some environmental influences are themselves made up of the behaviors of others (e.g., community norms) [14]. Thus, behavioral economics has the potential to be an important enabler of sustained behavior change, especially in technology-mediated environments. Behavioral economics also offers means to obtain a deeper understanding of how IS and the design of IS can influence users. Primarily because effective persuasive communication is also about correctly interpreting the purpose of an IS. Although, the persuasive communication can be disrupted by the noise sometimes created by people's cognitive biases [9]. 
As such, the educational approach and the assumption that people are rational actors prevalent in persuasive systems design and most IS-related theories such as the technology acceptance model (TAM) [40] is not the most effective approach to driving (behavior) change [37, 38, 39]. Rather, an understanding of people's inherent biases and examining how cues provided by technology influence users' online behavior can be more useful for stimulating change (e.g., [42], [43], [50], [56]). Especially, as results from Adomavicius et al. [43] showed that biased output from recommender systems can significantly influence users' preferences and their ratings of products.

The review asked one main question: "How can behavioral economics enhance understanding of users and their interactions with information systems?" We turned to the major IS journals to examine behavioral studies specific to IS. We were particularly interested in studies investigating behavioral economic principles related to valuation options, how cognitive stimuli influence users' choices, and how these can be explained by use, user and technology contexts outlined in the PSD model [7].

In terms of coverage, the findings suggest that: 1) There is great potential in enhancing research in the two fields especially as one considers how cognitive, emotional and environmental factors affect decision-making and the other is about information processing for decision making. This means that designers of intervention programs (whether digital or not) should focus not only on the desired (behavior) change, but also antecedent variables such as saliency, individual beliefs, awareness and so forth [59]. 2) There has been an increase in studies integrating behavioral economic principles in IS in recent years, the majority of which have focused on online retail stores [44], [45], [47] and recommender systems [42], [43], [53]. 3) Considering some of the limitations of IS, behavioral economics in its grounding on cognitive theories as presented in the reviewed studies, offers possibilities to enhance both the design and implementation of IS (including persuasive systems). Considering persuasive design strategies such as goal-setting, self-monitoring, social support have been identified as effective tools in weight management programs [8], [15], integrating these with techniques that encourage users to make self-beneficial decisions can enhance self-directed change through digital interventions [12]. Finally, 4) the decision-making process is not consistent. The study of behavioral economics principles in most cases should involve field and/or experimental tests to determine the underlying theoretical relationships in order to enhance the clarity of the studies and the principles applied.

The main IS journals were chosen because major contributions in a particular field are likely to be in the leading journals [34] and studies accepted in these forums are usually concise and comprehensive, detailing all the relevant aspects of the particular phenomena studied. Although, Webster and Watson [34] also suggest searching for articles elsewhere after the initial search in the major journals. In this study, our search was limited to only the basket of eight journals. We concentrated on the major journals because our interest was in studies that primarily focus on IS-related phenomena and the interactions between users and technology. Thus, we excluded from our review behavioral economics studies from other sources such as psychology and marketing (some of these were covered in the background section). Consequently, this review can be considered as the first attempt to synthesize behavioral economics studies from the 
major IS journals. Furthermore, our study has also considered the limitations of IS (including persuasive systems) research and suggested ways behavioral economics, with its focus on judgment and decision making, can help to mitigate these limitations.

In behavioral economics, the behavioral assumption is that people often act irrationally [9] and not all their actions can be reasonable and/or according to predefined criteria. The prevailing environment and one's emotional state affects decision-making. The persuasive element in behavioral economics lies in the presentation of choices in a way that leverages people's decision making processes; thus, encouraging them to make self-beneficial choices [37]. Consequently, behavioral economics can be used to investigate the scope of decisions regarding finances, health, and dietary choices that people make [9]. Although, it is important that decision biases are controlled given their strengths, especially in technology-mediated settings. If left uncontrolled, they trigger non-rational decision making, which results in sub-optimal decisions that can proactively be exploited to influence users [41]. Therefore, the psychological barriers that prevent desired behaviors should be understood and this knowledge incorporated into systems design. Control over (or even moderating), decision biases in digital interventions enables the enforcement of their persuasive power on a cognitive level [41].

\subsection{Limitations and Future Research}

For this study, we concentrated only on articles from the major IS journals and as comprehensive as these are, they do represent all the relevant information. Especially, when one considers that behavioral economics is a relatively new field and IS research is itself multidisciplinary so there may be other relevant studies outside the IS realm. For example, examining articles from well-known conferences, other disciplines journals and workshop proceedings. Secondly, our search was meant to produce a large number of articles for review. Therefore, including additional terms in the search string (e.g., known behavioral economic principles (cognitive biases prevalent in judgement and decision-making) such as framing, priming, incentives etc.) and searching in other online libraries and databases, a highly-focused pool of potential articles for review could have been found. Lastly, in persuasion context analysis since the articles did not prescribe to persuasive systems design, interpretive categorization, which may be subjective, was used.

In section 4, we positioned the behavioral economics literature based on context analysis and although there were similarities in approach, the studies analyzed were not about behavior change, which is a key concept in persuasive systems research. Inherently, they do involve change, but the coverage of the change and description of the changing element was limited. Additionally, most of the studies did not consider different user characteristics and how these differences may lead to varied responses to stimuli. Although, the studies on framing (see Table 1) did investigate how framing product or service offerings differently can influences users' choices. Through this, it could be possible to learn the effects of behavioral economic principles on different users if demographic variables that differentiates them are collected. Therefore, in context analysis, as viewed from the persuasive systems domain, not all factors could be applied which has implications for the findings. 
Further research to extend the scope of the search is planned and specifically to investigate how behavioral economic principles can be integrated with the principles of persuasive systems design. As most of the studies included in the current review focused on examining the effects of the different stimuli on users' preferences and/or choices, a potential avenue for future research would be to implement some of the principles in actual systems and study the subsequent effects. For example, how varying the allocation and rate of rewards combined with social support in incentive schemes could influence goal achievement. Or how gamification which integrate behavioral elements could be used in systems to encourage collaboration. Furthermore, the reviewed studies were diverse in nature. Some focused on behavioral IS and others on the economics of IS. Future research could examine whether there are any differences in the adoption of behavioral economics between different disciplines and the resulting implications.

\section{Conclusions}

In IS research, behavioral economics is a field that has been gaining in popularity in the last decade. This study documents a review of behavioral economics in the major IS journals. The purpose was to present an overview of the field and how it has been used to investigate IS-related phenomena in order to identify relevant research issues or unaddressed areas. We analyzed 15 relevant articles from an initial total of 919 articles found in scientific libraries. Based on this, the articles were classified according to context analysis (use, user and technology contexts) and the major behavioral economics principle investigated that were also defined. The main findings from the review are the importance of understanding how various contextual factors influence decision making (especially in IS use context), the factors which lead to sub-optimal decisions and influence how information is processed. The review, although not comprehensive, presented techniques for designing around user biases and represents a step toward understanding decision making in technology-mediated settings and may support the development of (persuasive) strategies that can help mitigate the various biases.

\section{References}

1. H. A. Simon, "Theories of Decision-Making in Economics and Behavioral Science," Am. Econ. Rev., vol. 49, no. 3, pp. 253-283, 1959.

2. D. Kahneman, "Maps of Bounded Rationality: Psychology for Behavioral Economics," Am. Econ. Rev., vol. 93, no. 5, pp. 1449-1475, 2003.

3. M. A. Prince, K. B. Carey, and S. A. Maisto, "Protective behavioral strategies for reducing alcohol involvement: A review of the methodological issues," Addict. Behav., vol. 38, no. 7, pp. 2343-2351, Jul. 2013.

4. T. Thorgeirsson and I. Kawachi, "Behavioral economics: merging psychology and economics for lifestyle interventions.," Am. J. Prev. Med., vol. 44, no. 2, pp. 185-9, Feb. 2013.

5. W. Pesendorfer, "Behavioral Economics Comes of Age: A Review Essay on 'Advances in Behavioral Economics,”’ J. Econ. Lit., vol. 44, no. 3, pp. 712-721, Sep. 2006. 
6. M. Oduor and H. Oinas-kukkonen, "Behavioral Economics in Information Systems Research: A Persuasion Context Analysis," in Proceedings of the 19th International Conference on Enterprise Information Systems - Volume 3: ICEIS, 2017, pp. 17-28.

7. H. Oinas-Kukkonen and M. Harjumaa, "Persuasive systems design: Key issues, process model, and system features," Commun. Assoc. Inf. Syst., vol. 24, no. 1, p. 28, 2009.

8. T. Lehto and H. Oinas-Kukkonen, "Persuasive features in web-based alcohol and smoking interventions: a systematic review of the literature.," J. Med. Internet Res., vol. 13, no. 3, p. e46, Jan. 2011.

9. D. Ariely, "Predictably irrational: the hidden forces that shape our decisions," New York. NY, Etats-Unis HarperCollins Publ., 2008.

10. P. B. Goes, "Editor's Comments: Information Systems Research and Behavioral Economics," MIS Q., vol. 37, no. 3, pp. iii--viii, Sep. 2013.

11. L. Lenert, R. F. Munoz, J. E. Perez, and A. Bansod, "Automated e-mail messaging as a tool for improving quit rates in an internet smoking cessation intervention.," J. Am. Med. Inform. Assoc., vol. 11, no. 4, pp. 235-240, 2004.

12. M. L. A. Lustria, J. Cortese, S. M. Noar, and R. L. Glueckauf, "Computer-tailored health interventions delivered over the Web: review and analysis of key components.," Patient Educ. Couns., vol. 74, no. 2, pp. 156-173, Feb. 2009.

13. B. J. Fogg, Persuasive Technology: Using Computers to Change What We Think and Do. 2003.

14. B. S. Fjeldsoe, A. L. Marshall, and Y. D. Miller, "Behavior Change Interventions Delivered by Mobile Telephone Short-Message Service," Am. J. Prev. Med., vol. 36, no. 2, pp. 165 $173,2009$.

15. T. Toscos, A. Faber, S. An, and M. P. Gandhi, "Chick clique: persuasive technology to motivate teenage girls to exercise," in CHI'06 extended abstracts on Human factors in computing systems, 2006, pp. 1873-1878.

16. S. M. Kelders, R. N. Kok, H. C. Ossebaard, and J. E. W. C. Van Gemert-Pijnen, "Persuasive system design does matter: a systematic review of adherence to web-based interventions.," J. Med. Internet Res., vol. 14, no. 6, p. e152, Jan. 2012.

17. S. Purpura, V. Schwanda, K. Williams, W. Stubler, and P. Sengers, "Fit4Life: The Design of a Persuasive Technology Promoting Healthy Behavior and Ideal Weight," in Proceedings of the SIGCHI Conference on Human Factors in Computing Systems, 2011, pp. 423-432.

18. I. Ajzen, "Theories of Cognitive Self-RegulationThe theory of planned behavior," Organ. Behav. Hum. Decis. Process., vol. 50, no. 2, pp. 179-211, 1991.

19. R. E. Petty and J. T. Cacioppo, The elaboration likelihood model of persuasion. Springer, 1986.

20. A. Bandura, "Social Cognitive Theory. IN: Annals of Child Development," R Vasta, vol. 6, pp. 1-60, 1989.

21. R. Cialdini, "Descriptive Social Norms as Underappreciated Sources of Social Control," Psychometrika, vol. 72, no. 2, pp. 263-268, 2007.

22. A. K. Dey, "Understanding and Using Context," Pers. Ubiquitous Comput., vol. 5, no. 1, pp. 4-7, Feb. 2001.

23. T. C. Schelling, "Self-Command in Practice, in Policy, and in a Theory of Rational Choice," Am. Econ. Rev., vol. 74, no. 2, pp. 1-11, 1984.

24. A. Tversky and D. Kahneman, "Judgment under uncertainty: Heuristics and biases," Science (80-. )., vol. 185, no. 4157, pp. 1124-1131, 1974.

25. D. Kahneman and A. Tversky, "Prospect Theory: An Analysis of Decision under Risk," Econometrica, vol. 47, no. 2, pp. 263-291, 1979. 
26. E. Angner and G. Loewenstein, "Behavioral economics," in Handbook of the philosophy of science: philosophy of economic, Uskali Mäk., Amsterdam: Elsevier, 2012, pp. 641-690.

27. R. H. Thaler and C. R. Sunstein, Nudge. New Haven, Connecticut: Yale University Press, 2008.

28. S. Michie and S. Williams, "Reducing work related psychological ill health and sickness absence: a systematic literature review," Occup. Environ. Med. , vol. 60, no. 1, pp. 3-9, Jan. 2003.

29. K. Lunze and M. K. Paasche-Orlow, "Financial Incentives for Healthy Behavior: Ethical Safeguards for Behavioral Economics," Am. J. Prev. Med., vol. 44, no. 6, pp. 659-665, Jun. 2013.

30. I. Siva, "Using the lessons of behavioral economics to design more effective pay-forperformance programs," Am. J. Manag. Care, vol. 16, no. 7, pp. 497-503, Jul. 2010.

31. E. Avineri, "On the use and potential of behavioural economics from the perspective of transport and climate change," J. Transp. Geogr., vol. 24, pp. 512-521, Sep. 2012.

32. M. Crowley, A. Heitz, A. Matta, K. Mori, and B. Banerjee, "Behavioral Science-informed Technology Interventions for Change in Residential Energy Consumption," in CHI '11 Extended Abstracts on Human Factors in Computing Systems, 2011, pp. 2209-2214.

33. D. King, F. Greaves, C. Exeter, and A. Darzi, “'Gamification': Influencing health behaviours with games,” J. R. Soc. Med., vol. 106, no. 3, pp. 76-78, Mar. 2013.

34. J. Webster and R. T. Watson, "Analyzing the Past to Prepare for the Future: Writing a Literature Review," MIS Q., vol. 26, no. 2, pp. xiii--xxiii, Jun. 2002.

35. B. Kitchenham, "Procedures for performing systematic reviews," Keele, UK, Keele Univ., vol. 33, no. 2004, pp. 1-26, 2004.

36. J. Vassileva, "Motivating participation in social computing applications: a user modeling perspective," User Model. User-adapt. Interact., vol. 22, no. 1-2, pp. 177-201, 2012.

37. M. K. Lee, S. Kiesler, and J. Forlizzi, "Mining Behavioral Economics to Design Persuasive Technology for Healthy Choices," in Proceedings of the SIGCHI Conference on Human Factors in Computing Systems, 2011, pp. 325-334.

38. H. Brynjarsdottir, M. Håkansson, J. Pierce, E. Baumer, C. DiSalvo, and P. Sengers, "Sustainably Unpersuaded: How Persuasion Narrows Our Vision of Sustainability," in Proceedings of the SIGCHI Conference on Human Factors in Computing Systems, 2012, pp. 947-956.

39. C. DiSalvo, P. Sengers, and H. Brynjarsdóttir, "Mapping the Landscape of Sustainable HCI," in Proceedings of the SIGCHI Conference on Human Factors in Computing Systems, 2010, pp. 1975-1984.

40. M. L. Markus and C. Tanis, "The enterprise systems experience-from adoption to success," Fram. domains IT Res. Glimpsing Futur. through past, vol. 173, pp. 173-207, 2000.

41. E. C. Teppan and M. Zanker, "Decision Biases in Recommender Systems," J. Internet Commer., vol. 14, no. 2, pp. 255-275, Apr. 2015.

42. K. H. Goh and J. C. Bockstedt, "The Framing Effects of Multipart Pricing on Consumer Purchasing Behavior of Customized Information Good Bundles," Inf. Syst. Res., vol. 24, no. 2, pp. 334-351, Jul. 2012.

43. G. Adomavicius, J. C. Bockstedt, S. P. Curley, and J. Zhang, "Do Recommender Systems Manipulate Consumer Preferences? A Study of Anchoring Effects," Inf. Syst. Res., vol. 24, no. 4, pp. 956-975, Sep. 2013.

44. J. Y. Tsai, S. Egelman, L. Cranor, and A. Acquisti, "The Effect of Online Privacy Information on Purchasing Behavior: An Experimental Study," Inf. Syst. Res., vol. 22, no. 2, pp. 254-268, Feb. 2010. 
45. J. Wu and E. A. A. Gaytán, "The role of online seller reviews and product price on buyers' willingness-to-pay: a risk perspective," Eur. J. Inf. Syst., vol. 22, no. 4, pp. 416-433, 2013.

46. J. Park, P. Konana, B. Gu, A. Kumar, and R. Raghunathan, "Information Valuation and Confirmation Bias in Virtual Communities: Evidence from Stock Message Boards," Inf. Syst. Res., vol. 24, no. 4, pp. 1050-1067, Jul. 2013.

47. C.-M. Chiu, E. T. G. Wang, Y.-H. Fang, and H.-Y. Huang, 'Understanding customers' repeat purchase intentions in B2C e-commerce: the roles of utilitarian value, hedonic value and perceived risk," Inf. Syst. J., vol. 24, no. 1, pp. 85-114, Jan. 2014.

48. R. Legoux, P.-M. Leger, J. Robert, and M. Boyer, "Confirmation biases in the financial analysis of IT investments," J. Assoc. Inf. Syst., vol. 15, no. 1, p. 33, 2014.

49. I. D. Constantiou, C. Lehrer, and T. Hess, "Changing information retrieval behaviours: an empirical investigation of users/' cognitive processes in the choice of location-based services,” Eur J Inf Syst, vol. 23, no. 5, pp. 513-528, Sep. 2014.

50. J. Blechar, I. D. Constantiou, and J. Damsgaard, "Exploring the influence of reference situations and reference pricing on mobile service user behaviour," Eur. J. Inf. Syst., vol. 15, no. 3, pp. 285-291, 2006.

51. C. M. Angst and R. Agarwal, "Adoption of Electronic Health Records in the Presence of Privacy Concerns: The Elaboration Likelihood Model and Individual Persuasion," MIS Q., vol. 33, no. 2, pp. 339-370, Jun. 2009.

52. C. F. Blanco, R. G. Sarasa, and C. O. Sanclemente, "Effects of visual and textual information in online product presentations: looking for the best combination in website design," Eur J Inf Syst, vol. 19, no. 6, pp. 668-686, Dec. 2010.

53. Y. E. Lee and I. Benbasat, "Research Note-The Influence of Trade-off Difficulty Caused by Preference Elicitation Methods on User Acceptance of Recommendation Agents Across Loss and Gain Conditions," Inf. Syst. Res., vol. 22, no. 4, pp. 867-884, Apr. 2011.

54. N. Lankton and J. Luft, "Uncertainty and Industry Structure Effects on Managerial Intuition About Information Technology Real Options,” J. Manag. Inf. Syst., vol. 25, no. 2, pp. $203-$ 240, Sep. 2008.

55. P. A. Ubel, "Q \&amp; A with R. Thaler on What It Really Means to Be a Nudge | Psychology Today,” 2015. [Online]. Available: https://www.psychologytoday.com/blog/criticaldecisions/201503/q-r-thaler-what-it-really-means-be-nudge. [Accessed: 15-Apr-2015].

56. X. Ma, S. H. Kim, and S. S. Kim, "Online Gambling Behavior: The Impacts of Cumulative Outcomes, Recent Outcomes, and Prior Use,” Inf. Syst. Res., vol. 25, no. 3, pp. 511-527, Jun. 2014.

57. B. Q. Liu and D. L. Goodhue, "Two Worlds of Trust for Potential E-Commerce Users: Humans as Cognitive Misers,” Inf. Syst. Res., vol. 23, no. 4, pp. 1246-1262, Jun. 2012.

58. P. Dolan, M. Hallsworth, D. Halpern, D. King, and I. Vlaev, "Mindplace: influencing behaviour through public policy.," 2010.

59. H. Spittaels, I. De Bourdeaudhuij, J. Brug, and C. Vandelanotte, "Effectiveness of an online computer-tailored physical activity intervention in a real-life setting.," Health Educ. Res., vol. 22, no. 3, pp. 385-396, Jun. 2007. 